\title{
Psychosocial Stressors and Help-Seeking Behavior \\ among Undergraduate Student Teachers in Tanzania
}

\author{
Hezron Z. Onditi (Corresponding author) \\ Dept. of Educational Psychology and Curriculum Studies, Dar es Salaam University \\ College of Education \\ PO Box 2329, Dar es Salaam, Tanzania \\ E-mail: hezndit@yahoo.com \\ Ikupa Moses \\ Dept. of Educational Psychology and Curriculum Studies, Dar es Salaam University \\ College of Education \\ PO Box 2329, Dar es Salaam, Tanzania \\ E-mail: ikumoses@gmail.com \\ Faustine B. Masath \\ Dept. of Educational Psychology and Curriculum Studies, Dar es Salaam University \\ College of Education \\ PO Box 2329, Dar es Salaam, Tanzania \\ E-mail: fbm85bhr@gmail.com
}

Doi:10.5296/ijld.v4i1.5087

URL: http://dx.doi.org/10.5296/ijld.v4i1. 5087

\begin{abstract}
This study explored undergraduate student teachers experiences on psychosocial stressors, how they resolve the stressors, and the level of utilization of college help or support resources. A self-report questionnaire was administered to a total of 187 first year, second year and third year student teachers $(M=25 \& S D=3.38)$ from Dar es Salaam University College of Education, Tanzania. Regardless of gender, student teachers reported to have had high level of stressful experiences to the extent of needing assistance. And the longer the students stay in the college the more stressful experiences they are likely to encounter. Although students would most often prefer face to face followed by making a telephone call in seeking for help, there is a low utilization of formal college help services such as counseling compared to the informal sources of help like fellow students. And a lack of awareness, ethical concerns, and cultural factors emerged as the major barriers to help-seeking from the formal college sources of help. The results of this study provide insight for developing a comprehensive and holistic intervention programs that could buffer students from stress and its associated maladies.
\end{abstract}

Keywords: Psychosocial stressors, Help-seeking behavior, Informal sources of help, Formal sources of help. 


\section{Introduction}

Stress and its associated negative impacts have been a focus of scientific studies over decades. Barry (1998) and Lahey (2004) argued that stress, which refers to a subjective feeling of tension in response to threatening environmental events (stressors), can severely disrupt body functioning and create greater demand on an individual's health. For example, under stress, individuals express changes in appetite, sleep pattern, headache, and difficulty in concentrating and lose of the ability to think clearly (Bourne, 2005; Barry, 1998; \& Lahey, 2004). College life is a stressful time for many students. Santrock (2000) and Sax (1997) demonstrated that about $25 \%$ of college students in most of the developed countries experience burn out. Similarly, a study from a developing country by Seif (2011) revealed that about 53\% of university students who were interviewed reported to have experienced stress. This suggests that college and university students from both developed and developing countries are vulnerable to stressors. However, the level of stress and reaction to stressful event may vary across individuals, stressors and context (Lahey, 2004).

The common "psychosocial stressors," which according to this study refers to psychological and social events that may lead to stress among college and university students include: academic, financial hardships, relationship, time management, health concerns, social problems, future career plans, and personal problems (Seif, 2011; Straub, 2007). However, with the advancement of technology and the ongoing changes in policies in higher education, the severity and number of stressors will likely continue to emerge and vary across contexts. Seif (2011) argued that a number of environmental demands compel individual students to negotiate their way beyond their ability to cope as a result causing them to experience considerable distress. For example, adjustment to a new college environment is more stressful especially among fresh students (Mechanics, 1962; D'Zurilla \& Sheedy 1991). In a similar vein, continuing students may also suffer from multiple stressors on campus. If not addressed, stress may constitute one of the reasons for students' failure, postponement of studies or exams, drop out and push out or discontinuation from studies.

Dealing with stressful situation may differ from one individual and from one context to another. Individuals' reaction to stress is influenced by a number of factors including prior experience with the stress, the degree to which an individual can predict and control the stressor, the availability of social support, and personal variables (Bourne, 2005; D'zurilla \& Sheedy, 1991; \& Lahey, 2004). For example, studies about prevalence and correlates of depression, anxiety and suicidal among university students found out that female students are likely to screen positive for major depression and anxiety disorders compared to male students (Eisenberg, Gollust, Golberstein, \& Hefner, 2007; Sax, 1997; \& Seif, 2011). Additionally, women exhibit stress more overtly than males (Hyde \& Plant, 1995; Thomas \& Williams, 1991), and they are more likely than their counterparts to experience lasting reaction to traumatic events (Lahey, 2004; \& Sax, 1997). However, variations among individuals, level of stressor and context may determine individual's ability to cope with stressful events or situations.

Given the negative impacts of stress on college students, it was important to explore students' help-seeking behavior, that is, the tendency of students to reach out for assistance amidst stressful situations. In this study, help-seeking behavior will include the use of external coping strategies in alleviating stress. Help-seeking behavior can be formal or informal (Tung, 2011). Whereas formal help-seeking behavior include individuals' tendency to seek for support from the existing college help or support services, such as counseling unit and academic advisors ; 
informal help-seeking involves discussing the problem with family members, friends, colleagues or roommates.

According to cognitive stress theories, for example Lazarus and Folkman (1984), a situation is considered to be stressful if it is potentially harmful and if the individual perceives that his or her internal and external coping resources, which are available, are insufficient to confront the impact of stress. The theory views stress as a transaction between individuals and their environments. Lazarus and Folkman emphasized that when confronted with environmental demands, individuals tend to evaluate whether the demands pose a potential threat and whether he or she has a sufficient coping or help resources to deal with the problem. If they find the environmental demands more threatening, and at the same time view their coping resources as inadequate, they perceive themselves to be under stress. Thus, both the evaluation of a situation as stressful, and the intensity of the stress experience depend to a large extent on the individual's evaluation of his or her repertoire of coping or help resources. In this study the appraisal of stress starts by student teachers identifying stressful events ever occurred during their lifetime at the college and the associated coping strategies that were applied. In analyzing coping strategies, researchers distinguished between external and internal coping resources (Stroebe, 2000; \& Lahey, 2004). On one hand, external coping or help resources include resources external to an individual which are potentially helpful in alleviating stress. On the other hand, internal coping resources consist of the personality traits, abilities and skills which enable people to cope with the stress. Personality characteristics may either decrease or increase individuals' ability to reach out for help (Stroebe, 2000). For example, hardy personality individuals believe that they can influence events in their lives, are involved in events and activities which have influence in their lives and can advocate for change. Regardless of the personality traits, Stroebe maintained that the availability of support services and their utilization is linked with a reduced risk of mental illness.

Generally, colleges and universities tend to have students' help or support resources, which according to this study refer to the external formal support services, which are potentially helpful in buffering students from stress. Studies by Kalonge (2007), Mosha (1990), and Seif (2011) reported that students from the University of Dar es Salaam - Mwalimu Nyerere campus in Tanzania are overwhelmed by many stressors including academic, financial hardships, career planning, relationship and accommodation. Despite the availability of formal help or support resources such as counseling and academic advisors, these studies have indicated that these facilities are not fully utilized by students (Seif, 2011), instead most of students rely on intimate friends and relatives in getting help (Mosha, 1990). We know that having help or support resources is one thing, and the utilization of the existing help resources is the most essential and important thing in addressing stress. In USA, the underutilization of counseling services by international students has been linked to many factors including stigmatization and lack of awareness about the existing college help services, cultural norms, language barrier, and issues of privacy and confidentiality (Hyun, Quinn, Madon, \& Lustig, 2007; Tung, 2011). However, it remains unclear to understand barriers to help-seeking behavior in a Tanzanian context. The question that this paper also tries to address from Dar es Salaam University college of education (DUCE) context.

Similar to other higher learning institutions, (DUCE) has a significant number of formal help or support resources to support students amidst various psychosocial problems, which could lead to stress. The college help resources include: Dean of students' office, counseling services, health center, academic advisors, instructors, administrative staff, auxiliary police, students' union, religious groups, just to mention a few. As we illuminated earlier, having help support 
resources in place is one thing, an effective utilization of the help resources is the most important part. Inspired by the recent homicide of a female student by a fellow male student at DUCE, students boycott, and other anecdotal information on distress among students, this descriptive study was undertaken to explore the level of stress experiences and help-seeking behavior among undergraduate student teachers from DUCE in Tanzania. Specifically, this study planned to answer the following five questions: 1) What is the extent of stress among undergraduate student teachers? 2) What are the most common critical psychosocial stressors experienced by student teachers? and how are they resolved? 3) To what extent do students use the college help or support resources? 4) What are the different methods of communication used or preferred by students in seeking for help when stressed? and 5) What are the potential barriers to help-seeking from the college help or support resources? Findings of this study are expected to inform practice and future research, especially from a Tanzanian context where empirical research in this area is at an infancy stage.

\section{Method}

\subsection{Research design and Participants}

This study employed a descriptive cross-sectional survey research design to explore undergraduate students' experiences on stress and how they deal with stressful situations. The design is powerful in obtaining data about a phenomenon across population characteristics within a particular point in time (Best \& Khan, 2006). A self report questionnaire was administered by the researchers to a total of 250 first year, second year and third year undergraduate student teachers randomly selected across the three faculties - Education, Humanities and Sciences from DUCE, in Tanzania. However, only 187 (75\%) students filled and returned the questionnaire, which were used for analysis.

Table 1. Demographic characteristics of the sample

\begin{tabular}{|l|l|l|l|l|l|l|l|}
\hline & Variable & Number & Percentage & Age & \\
\hline & & $(\mathrm{n})$ & $(\%)$ & Minimum & Maximum & $M$ & $S D$ \\
\hline Sex & Male & 107 & 57 & 20 & 40 & 25 & 3.38 \\
\hline & Female & 80 & 43 & & & & \\
\hline Year of study & $1^{\text {st }}$ year & 62 & 33 & & & & \\
\hline & $2^{\text {nd }}$ year & 62 & 33 & & & & \\
\hline & $3^{\text {rd }}$ year & 63 & 34 & & & & \\
\hline
\end{tabular}

\subsection{Measures}

A questionnaire consisting of twelve major items adapted from previous studies and literature review (Azen \& Walker, 2011; Batten \& Dutton, 2011; Hsu, 2005; Ang \& Yeo, 2004; Tinsley, de St Aubin \& Brown, 1982) was filled by 187 students. Given the nature of the research questions, the questionnaire was largely made up of categorical variables (Azen \& Walker, 2011). The first four items were used in gathering demographic information mainly sex, year of study, faculty and age. The next three items were used in finding out information about students' experiences with stress and how they deal with stressful situations. In particular, the first question explored about the extent or experiences of stress among college students "... have you ever experienced a problem that made you feel upset, off-mood, loosing energy and control to the extent of feeling a need for a support or help...? , and the response was either "yes" or "no." The second question explored about the most critical stressful problems experienced by college students. Participants checked the most common stressful experiences from the list and were all asked to describe any other stressful experiences through an open 
ended question. In addition, question three "how did you resolve the stress...identified above?" helped in understanding some of the strategies employed by students in dealing with stressful events. Apart from checking from the provided list of the potential strategies used in resolving stress, participants were also required to describe any other useful strategies through an open question.

To find out to what extent students' use the college support or help resources, two questions were used. First, "have you ever asked for help or support from the college sources of support during stressful situation?" and second, "how often have you ever used or asked for help from the following college sources of support during stressful situation?" The responses were either "almost always, sometimes, rarely or never." Similarly, two items with various lists of communication methods were used in exploring approaches of communication employed by students and the approach/es they would like to use in seeking for help from the college help sources. While the first question asked about "what methods of communication did you use in seeking for help from the college... when you were in stressful situation?", the second question asked on "... what method/s of communication would you likely prefer to use in seeking help from the college help resources when you are in stressful situation?" And the response was either "almost always, sometimes, rarely or never."

Furthermore, the last question "what are the barriers you face or do students commonly face in seeking help from the available college help or support resources when in a stressful situation?" was used to identify some potential barriers to help-seeking from the college support resources, and participants checked all items, which applied to them from the list of barriers. Moreover, participants were also asked to describe any other potential barriers through an open question.

\subsection{Ethical issues}

After getting a research approval from the institution, an informed consent was obtained from all participants after a verbal explanation by the researchers on the aim and objectives of the study, anonymity and confidentiality processes (Freeman \& Mathison, 2009; Flick, 2009). Thus, researchers administered the questionnaire separately to a diverse class of first, second and third year students in the first 30 to 45 minutes of the lecture hours. Particularly, the respective classes were purposively chosen because the courses were compulsory and included all students from the respective cohort. This composition improved the level of representation of participants.

\subsection{Analysis}

Data were coded and analyzed using SPSS, which is a computer quantitative data analysis software (Pallant, 2010). Descriptive categorical data analysis techniques were employed (Azen \& Walker, 2011). This helped in identifying the frequencies and percentages of the various categorical study variables. To compare the frequencies between the categorical variables of interest, and differences by sex and years of study, crosstabulation (e.g., 2 by 2 table of Sex*Stress experience, and 3 by 2 table of Year of study *Stress experience) and Chi-square tests for independence were used. And the major assumption for the Chi-square test, which expects cell frequencies of 5 or greater, was checked (Pallant, 2010; Azen \& Walker, 2011). After an open free coding and axial coding that led into the development of themes (Pascale, 2011), the qualitative information obtained through the three open ended questions was deductively analyzed based on the previous literature and the existing categories of themes. Generally, results were organized and presented in bar graphs. 


\section{Results}

\subsection{Undergraduate students' stress experiences}

One of the major interests of this study was to explore the extent of stress experiences among undergraduate student teachers. Results showed that about $70 \%$ of undergraduate student teachers at DUCE reported to have experienced stress, while 30\% reported to have had no stressful experience that would lead to a need of assistance or help. By gender, it was found that $70 \%$ of male students reported stressful experiences compared to the $69 \%$ of their female counterparts. Using a 2 by 2 crosstabulation (i.e., Sex*Stress experience), and without violating the assumptions of a Chi-square test, there was no a statistically significant difference between gender and general stress experiences, $\chi^{2}(1, n=187)=.001, * * p>.05$, phi $=-.01$. With a negligible effect size of only one percent, male and female student teachers did not differ with respect to general stressful experiences at college.

Similarly, by the year of study, it was found that $53 \%$ of the first year students, $66 \%$ of the second year students and $70 \%$ of the third year students reported to have had stress experiences.

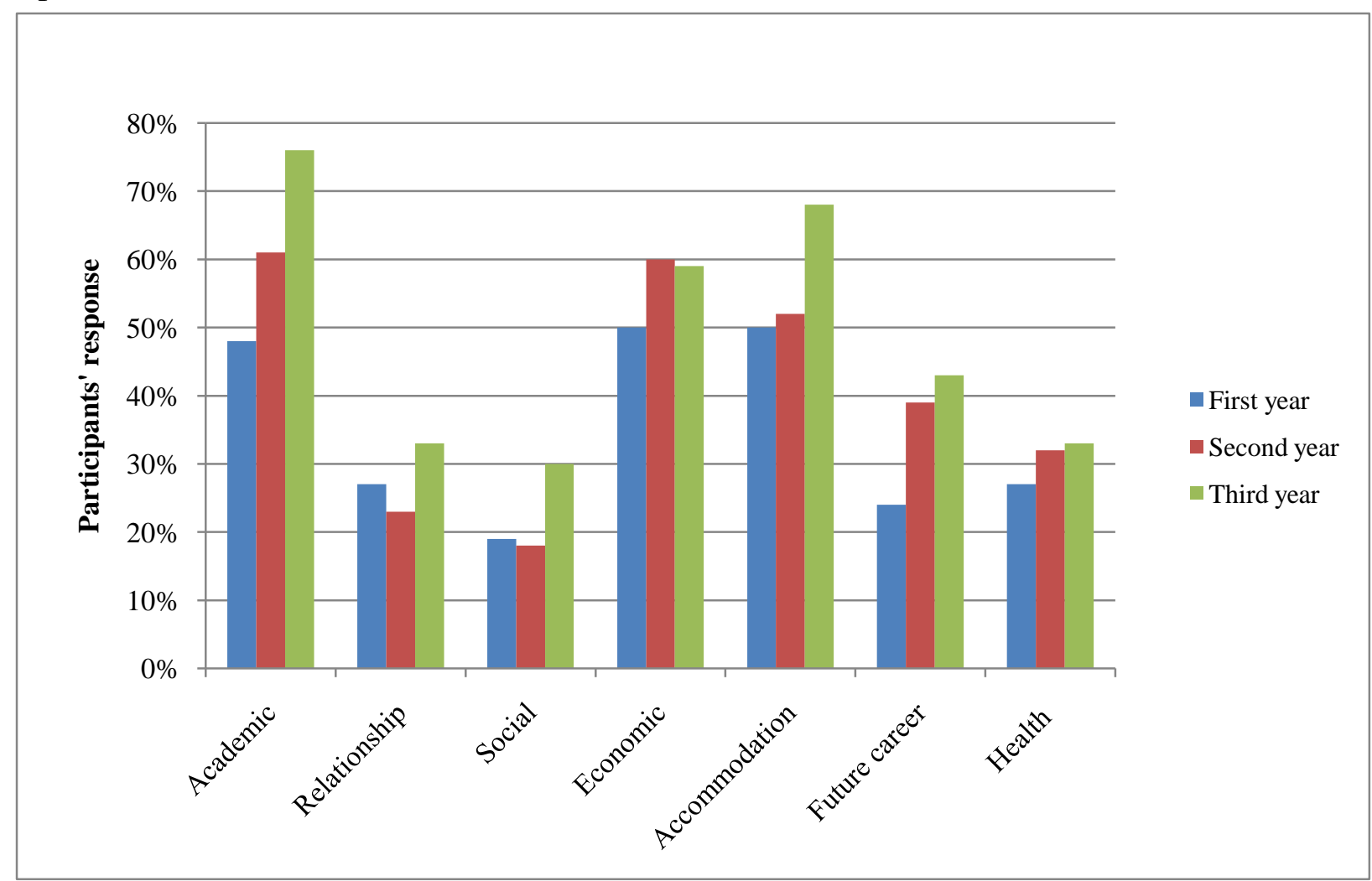

Figure 1. Levels of psychosocial stressors across years of study

However, with all basic assumptions of a Chi-square met, there was a statistically significant difference between the year of study and stress experiences, $\chi^{2}(2, n=187)=19.26, * * p<.05$. And a small effect size of .23 was obtained using Cramer's V. This indicates that only $23 \%$ of the variations in frequency counts of the two responses 'yes' and 'no' can be explained by stressful experiences. In particular, the longer the students stay at the University the more stressful they become. In order of severity, generally, majority of students across years of study reported academic, accommodation, and financial hardship as the major stressors, followed by future career, health, relationship and social related problems. With an exception of other psychosocial stressors where they ranked last, first year students appeared to experience more of the relationship and social problems compared to the second year students. 
From open and axial coding of students' responses to an open ended question (Pascale, 2011), the following are the other critical stressors identified by students: lack of conducive learning materials and environment, harsh treatment from lecturers, political matters and pregnancy.

\subsection{How students used to resolve different stressful experiences}

Apart from identifying the most critical stressful experiences among college students, this study also explored different ways used by students in resolving different stressful experiences encountered while at the college. Figure 2 represents findings on how students deal with the stressful situations.

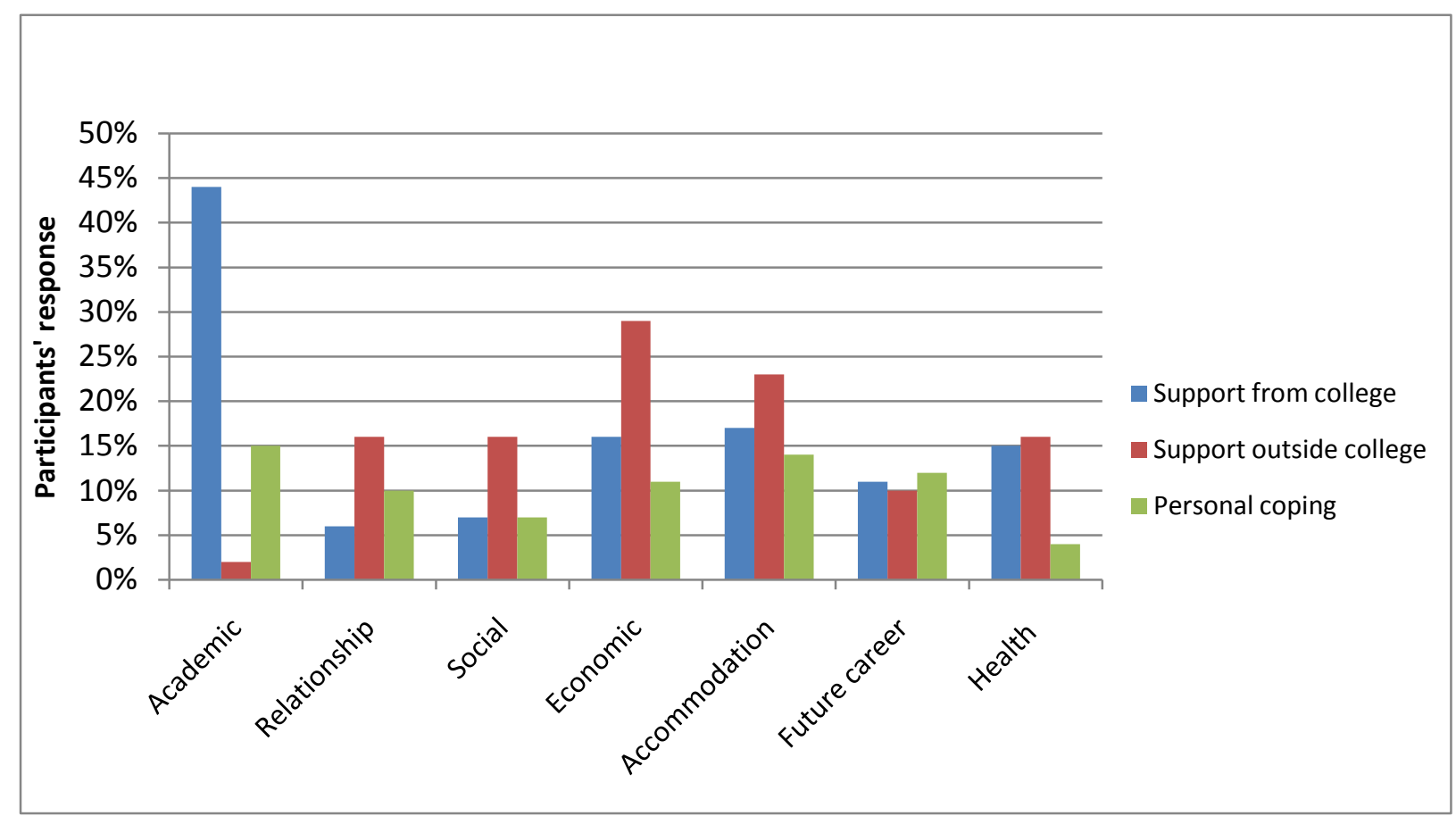

Figure 2. How student teachers respond to stressful experiences

As presented in figure 2, with an exception of academic stress related problems where students would seek support from college formal help resources, most of the students seem to rely on support from outside college when it comes to other stressful experiences. Some of the students also tend to depend on personal coping strategies in resolving stress. In addition, after doing an open and axial coding of students' responses to an open ended question (Pascale, 2011), the following are the other specific approaches used by students in dealing with stressful situations: informal approaches such as sharing with friends, guardians/parents, spouses, engaging in doing petty business and praying; and formal approaches such as seeking support from lecturers.

\subsection{Utilization of college support or help resources}

Participants were asked if they have ever asked for help or support from the college help sources amidst stressful situation. Generally, it was found that about $67 \%$ of students have never asked for help from the college support or help resources.

More specific, participants were asked the extent to which they have used college sources of support. Results are presented in the following bar graph. 


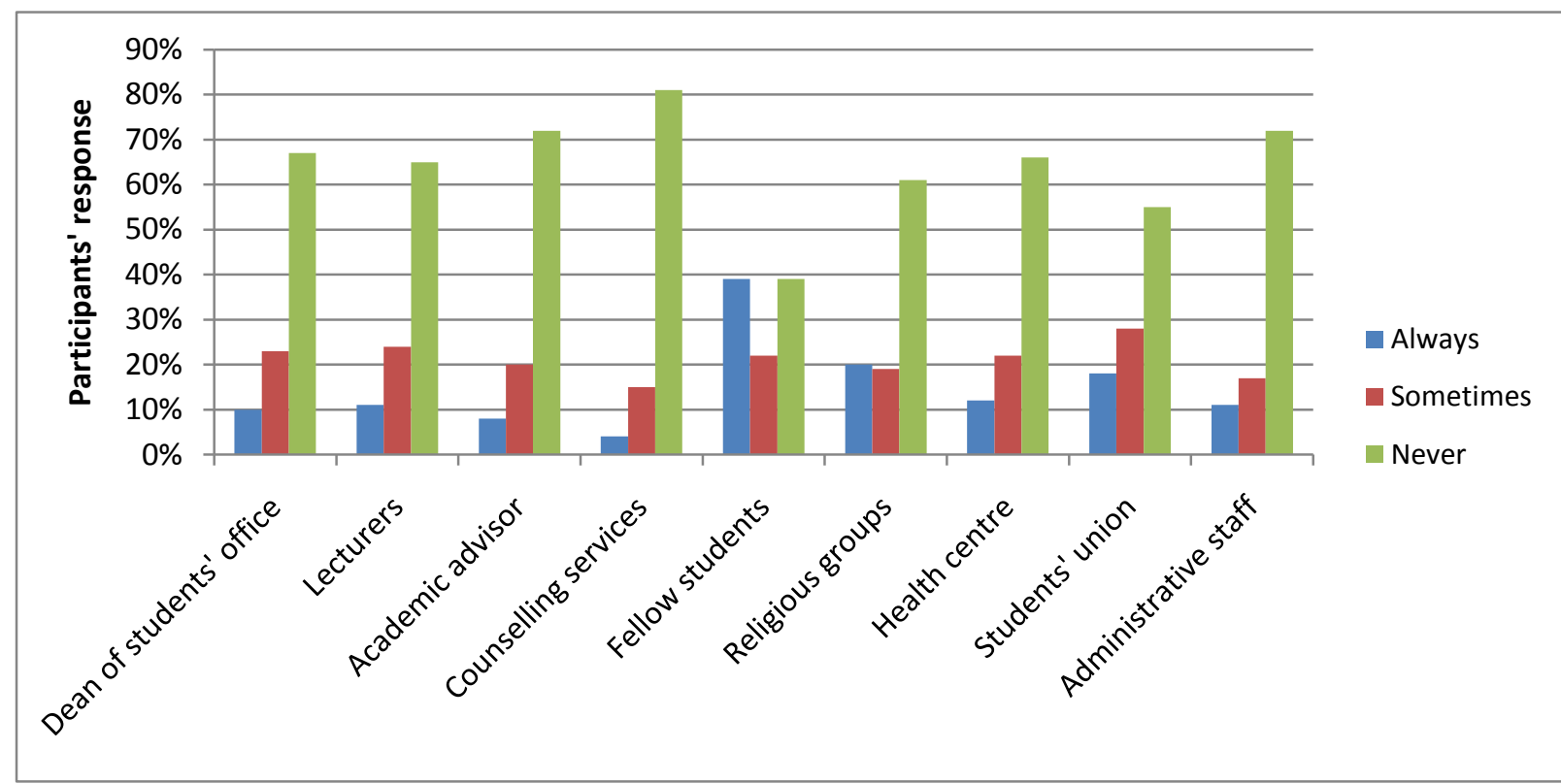

Figure 3. Students' use of different college help resources

From figure 3, taking an aggregate percentage of always and sometimes: it was revealed that students mainly rely on informal sources of help such as their fellow students $61 \%$. This was followed by reliance on religious groups 39\% and students' union 36\%. The use of other college support resources was as follows: Lecturers/Instructors 35\%, Health centre 34\%, Dean of students' office $33 \%$, Academic advisors $28 \%$, Administrative staff $28 \%$, and Counseling services $19 \%$.

\subsection{Methods of communication used and preferred in seeking for help}

Participants were also asked about the methods of communication they used and the methods they would prefer to use in seeking for help from college sources. Results are summarized in figure 4 and figure 5 respectively.

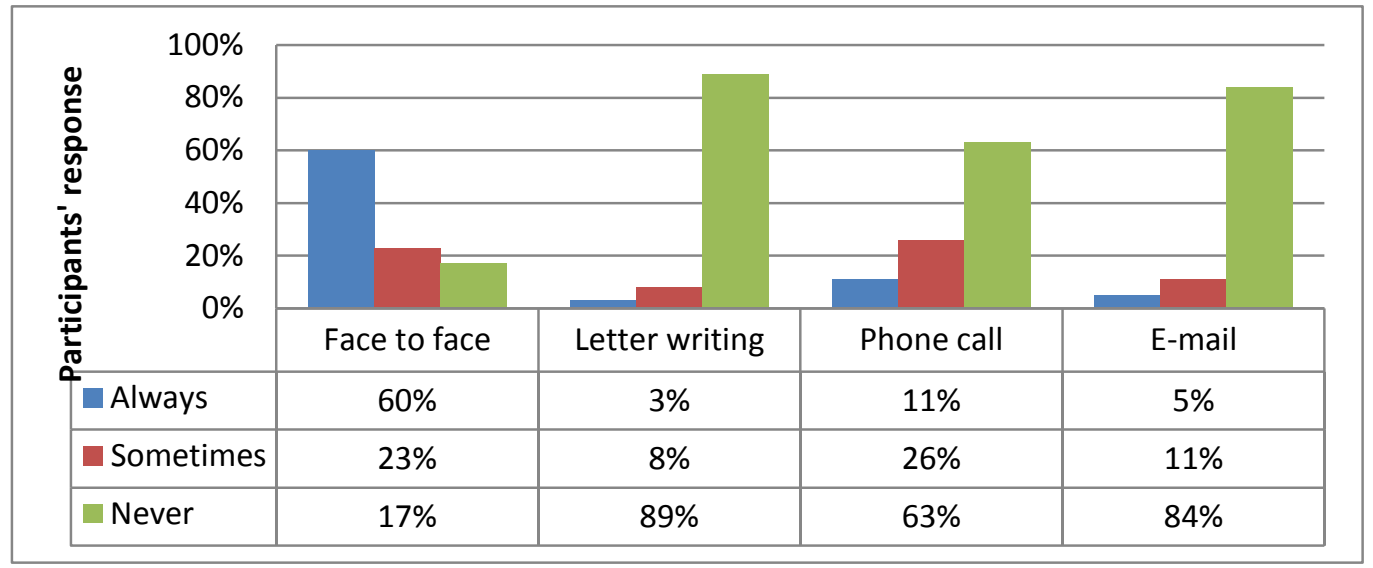

Figure 4. Methods of communication used by students in help-seeking

From a cumulative results of always and sometimes in figure 4, $83 \%$ of students used face to face in seeking for help. This was followed by phone calling $37 \%$, e-mail 16\%, and letter writing $11 \%$. Similarly, as presented in figure 5 below, face to face and phone calling communication methods remained to be the most preferred methods of communication among students when it comes to help-seeking compared to e-mail and letter writing communication 


\section{Macrothink Institute ${ }^{\text {TM }}$}

methods. From these results, face to face appears to be the most common of communication method used and preferred by students in seeking for help followed by phone calling. However, e-mail and letter writing were the least method of communication used or preferred by students in seeking for help when stressed.

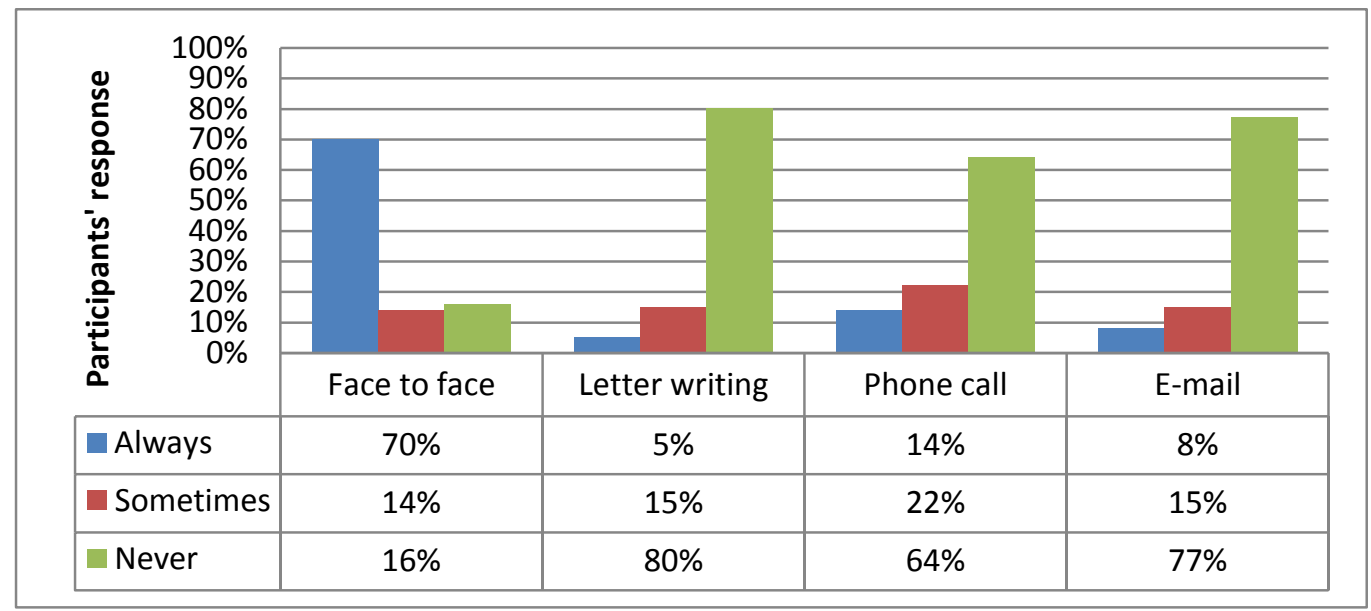

Figure 5. Methods of communication preferred by students in help-seeking

3.5 Barriers to help-seeking from the college support or help resources

Participants were asked to identify and describe some barriers to help-seeking from the college support or help resources.

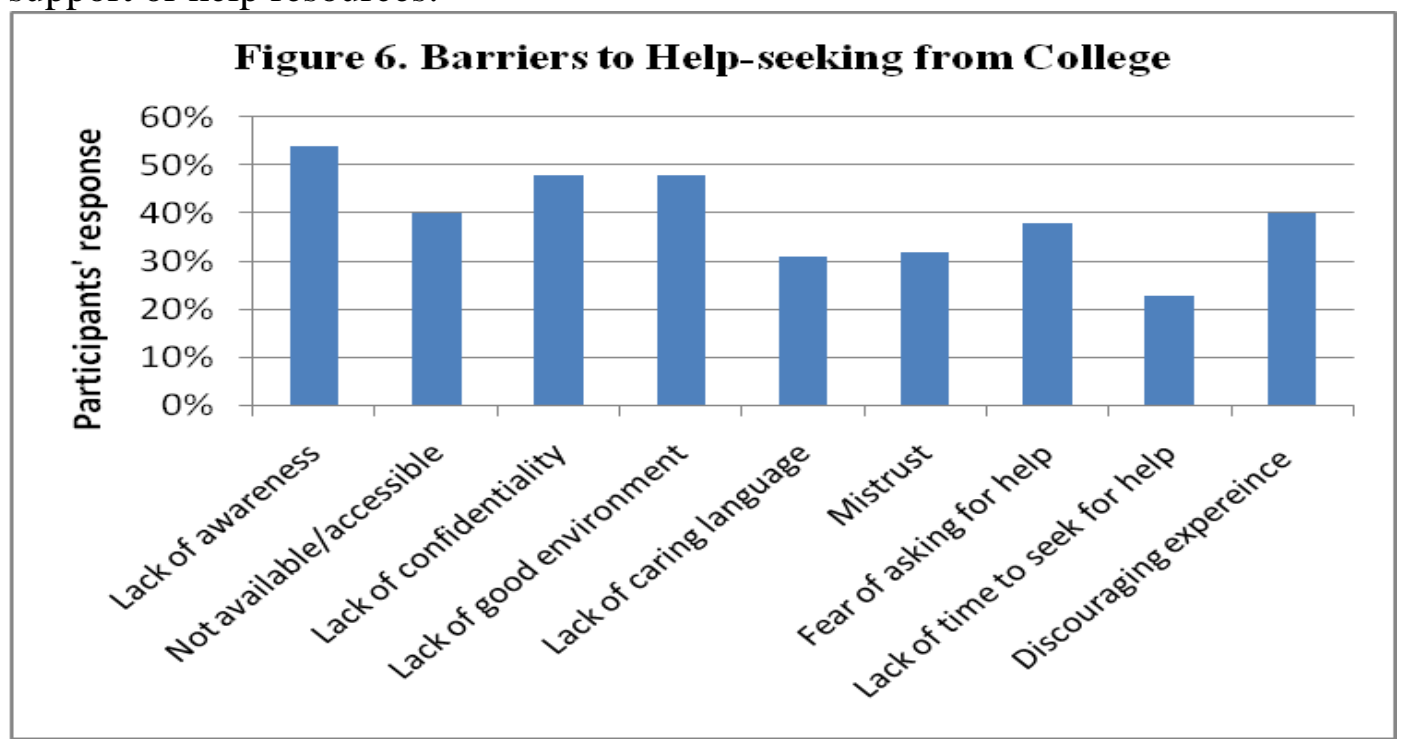

As presented in figure 6, only $23 \%$ of students indicated a lack of time to seek for help, that is, about $77 \%$ students appear to have time to seek for help. However, lack of awareness, confidentiality and conducive environment for sharing problems emerged to be the top barriers for help-seeking. Additionally, students also identified discouraging experience from colleagues, accessibility, fear of asking for help, mistrust, and lack of caring language as other potential barriers to help-seeking from the college sources. Furthermore, following an open and axial coding of students' responses to an open ended question (Pascale, 2011), the following are the other barriers to help-seeking as identified by students: insufficient number of qualified personnel, unfair treatment from the college sources of help, and cultural barriers in sharing personal problems. 


\section{Discussion}

The goal of this study was to explore the level of stress experiences and help-seeking behavior among undergraduate student teachers in Tanzanian context. In attempt to find out the extent of stress among student teachers, findings showed that majority of student teachers from DUCE that is about $70 \%$, both males and females have had stressful experiences in their life time on campus and would need help. Although this is consistent to Seif (2011) and Santrock (2000) who reported $53 \%$ and $25 \%$ levels of stress respectively, our findings appear to be comparatively high. Uniquely, our findings differ from other studies such as Abouseries (1994), Sax (1997) and Seif (2011) who reported that female students were more stressed than male students. The observed differences may be explained by various factors including differences in methodology, types of stressors, characteristics of participants and context.

Being the first study at DUCE, findings do not only provide insights on the severity of stress among students, but it also raises concern about the effectiveness and the efficiency of the college formal help resources. And if not adequately addressed, many students will continue to suffer from the negative impacts of stress that may lead to poor performance, postponement of studies, and drop out or discontinuation from studies, which is a loss not only to the individual student and his or her family, but also to the nation at large.

Counterintuitive to a common assumption that first year students are more likely to be stressed compared to students in senior levels, this study revealed that the longer students stay at the college the more stressful experiences they are likely to encounter. With regard to this study, third year students reported the highest level of stress across the seven psychosocial stressors included in the study, followed by second year and first year students. Given their seniority at the college, it is evident that the third year and second year students might have gone through various stressful experiences compared to their first year counterparts who were just in the second semester by the time of this study. For example, with regard to accommodation, first year students at DUCE are given first priority compared to the second and third year students who have to look for a private accommodation off campus. Moreover, being in their final year, some of the third year students struggle with unaccomplished academic goals such as the attainment of a good grade point average (GPA) and clearing the carried over courses, which, if not cleared will cost them another semester or an extra year in college something that students would not like. In addition, third years are more likely to be worried about future, especially on issues related to career and stable relationships that may lead into marriage. For example, anecdotal evidence shows that it is likely common among students from Tanzanian higher learning institutions to get married in their senior years. This tends to lead into more responsibilities, which may in turn contribute to stressful experiences.

In order of severity, academic, accommodation, and economic were the most psychosocial stressors experienced by student teachers at DUCE, which is similar to previous studies from developed countries (Abouseries, 1994; Santrock, 2000) that ranked academic and financial difficulties as the major stressors among university students. This is also consistent with previous studies such as Mosha (1990) and Seif (2011) from the University of Dar es Salaam-Mwalimu Nyerere campus in Tanzania. Generally, academic is the major core activities in higher learning institutions. As a result many students tend to prioritize academics over social and personal concerns (Li, Wong \& Toth, 2013). And we know that as students navigate through academic tasks such as assignments, tests, and examinations they become overwhelmed, anxious and more stressed. In a similar vein, meeting the deadlines, the fear of 
failure, low GPA, supplementary examinations, carrying over courses and discontinuation from studies usually tends to intensify the level of academic stress among college students.

Unlike the previous studies from other contexts, this study demonstrated accommodation to rank second in the list of stressors among student teachers at DUCE. This may be linked to the recent expansion in enrolment in Universities in Tanzania, which does not much with the available resources. This has resulted to the shortage of accommodation and other learning facilities in many campuses including DUCE. As a result, most of students, especially students in their senior years, are required to make arrangement for private accommodation off campus. This tends to be more stressful to most of the students, especially those who are coming from upcountry and from low social economic status families. To address the problem of accommodation, there is a need for the government and the University to develop a short term and a long term plan that may provide students with affordable and adequate accommodation within the campus or at the vicinity of the campus.

And with regard to economic life, majority of University student teachers in Tanzania depend on loan from the government. However, not all students are fortunate to get the loan from the government, and to the beneficiaries, the amount of the loan is insufficient to cover for both direct and indirect student's costs. Thus, a significant number of students are uncertain about their economic life leading to more stressful experiences. This is consistent to Eisenberg et al. (2007) findings that students who demonstrate high financial difficulties are more vulnerable to mental health problems. Given that student teachers will have to repay the loan post graduation, and provided that the government is currently able to employ all graduate teachers, there is a need to give adequate loan to all student teachers who are in need. This will not only help in addressing financial difficulties, but may also assist in reducing accommodation stressors as a result leading to concentration and improved performance in academics.

The other unique finding from the other stressors was that unlike the second year students, first year like third year students appeared to be more stressed by relationship and social issues. This may be explained by various factors. As newcomers, first years are in the transition period trying to adjust to the college culture, developing new relationships and friendships, which is sometimes more stressful. This indicates that first year and third year students may need more help on relationship and social issues compared to the second year students.

Regarding how students resolved different stressful experiences, with an exception of academic stressors where many students indicated to have sought support from college sources such as lecturers/instructors, presumably due to the intensity of the academic stress and inadequacy of personal coping resources (Lazarus \& Folkman, 1984), majority of student teachers demonstrated to seek support from informal sources for most of the psychosocial stressors such as relationships, social, economic and accommodation. And the major informal sources of support used by student teachers include sharing with friends, guardians/parents, spouses; engaging in doing petty business, part time jobs; and personal coping such as praying. Over reliance on informal sources of help than the formal sources is congruent to other research findings. For example, Ang and Yeo (2004), Barker (2007), Hsu (2005) and Piper and MacDonald (2008) demonstrated that majority of students would talk to their close friends and family members first on certain stressors before contacting other sources of help. As reported by undergraduate students in a study by Li, Wong and Toth (2013), professional help such as counseling is a last resort "when you feel that the other forms of support are not helping anymore" (p. 9). However, to provide optimal support, especially for social, relationship and 
academic concerns, some of the informal help supporters may need adequate training (Fallon \& Bowles, 2001; Hsu, 2005).

One of the unique finding is that to address economic concerns, some student teachers appeared to be involved in doing business and part time jobs while at the college. Although this might affect academic performance of some students, it is an effort worth promoting in the contemporary higher learning institutions characterized by financial hardships and stiff competition in the world of work. In addition, other students seemed to employ personal coping strategies such as praying in the midst of psychosocial stressors, which is congruent to Abdullah (2011). This also illuminates on a need to strengthen positive individual coping skills and to encourage students' involvement in religious groups.

Despite the existence of college formal help or support resources, their utilization by student teachers was revealed to be low, which corroborates findings by Li et al. (2013), Seif (2011), Barker (2007), and Hsu (2005). In particular, 67\% of student teachers reported to have never asked for help from formal college sources of help such as counseling and academic advisors. Rather, student teachers reported to prefer getting help from their friends, religious groups and student union. Barker (2007) and Hsu (2005) argued that students would prefer to seek help from their friends or peers, and least from academic supervisors. On one hand, the dependency on friends, religious groups and student union as sources of help may be linked with the attachment, shared common interests and ease accessibility to help sources unlike college formal support systems that require appointment and are characterized by power difference. On the other hand, other factors including students' attitude toward seeking formal help and formal help-seeking culture or experience and the nature of the stressors may also determine the use of various sources of help ( $\mathrm{Li}$ et al., 2013). For example, students would use college support services mainly on academic and to some extent on financial, accommodation and health concerns. Findings suggest for a need to strengthen peer support services, religious groups, student union services and promoting the use of other formal support services on campus.

The underutilization of the formal college sources of support may be linked to various factors. Lack of awareness of the existing college support services emerged to be the major barrier, which is similar to Chang (2008) study with Chinese undergraduate students. Although, student teachers are informed about help services during orientation week in their first year, many students are still unaware of some of the important formal college support resources for example counseling and academic advisors. This cast doubt on the effectiveness of the orientation and other help awareness education programs. For efficiency and effectiveness, there is a need for an ongoing awareness campaign, using different strategies and platforms on the college formal support resources.

Additionally, although $77 \%$ of students in this study seemed to have time to seek for help, lack of confidentiality and conducive environment appeared to be the second major barriers to help-seeking from the college sources. To be effective and to attract the users or clients, help services should be provided in an environment that respects clients' privacy and confidentiality of the shared information. This is consistent with Batten and Dutton (2011) findings that young tertiary students valued and used help sources that are "trustworthy, and that made them feel comfortable" (p.40). Lack of these ethical principles including mistrust and lack of caring language appeared to have made some students to shy away from using the existing formal college support resources such as counseling, academic advisors and dean of students' office. For the case of DUCE, the violation of ethics may be associated with an overlapping role of a counselor who is also an administrator. For efficiency and effectiveness, counselors should be 
independent from administrators. And good environment and adherence to ethical principles is not only essential but also important for the improved utilization and quality formal college support services.

Apart from awareness and ethical barriers, students also indicated cultural barriers to help-seeking. In particular, some students feared to ask help from formal college sources. This is consistent with Ang and Yeo (2004) who argued that cultural stigma and the likelihood of bringing shame to the family may explain why some Asian students are reluctant to use formal help services such as counseling. Similarly, Chang (2008) suggested that students' prior experience with the formal help services, their attitude towards formal help services, and the nature of stressors may predict the use of formal help resources. For example, about $40 \%$ of students in this study who reported to have had prior discouraging experiences with formal college help sources described them to be less caring and unavailable when needed. This could make some students to continue circumventing the use of formal college help resources or to demand an alternative method of communication to access help services from college.

Despite the advancement in information and communication technologies, majority of student teachers used and would still prefer to use the traditional face to face interaction followed by telephone method in seeking for help from college sources. This confirms Hsu (2005) argument that "when student teachers seek people for help, physical proximity is still important" (p.315). This can be explained by various factors, for example, in Tanzanian context, face to face is a more traditional and dominant cultural method of communication used in help-seeking, mainly from elders. In addition, for students, it is easy and cheap in terms of cost compared to other means whereby one has to find a phone with credit for calling, and a reliable access to internet for sending an e-mail text. However, the professional face to face help methods such as counseling would require well trained and qualified personnel. Findings suggest a need for an effective environment for face to face help services including professional counseling at the college.

Moreover, while some students indicated to use telephone call and electronic mail communication methods in help-seeking, letter writing is the least method of communication used or preferred by student teachers in help-seeking. The similar pattern though with low frequency was revealed by Hsu (2005). Given that letter writing may be too time consuming for students to wait for response, and due to the identified barriers to help-seeking behavior, which are connected somewhat to face to face interactions. We may argue for the integration of information and communication technologies (ICT) such as the establishing of a toll free line for telephonic counseling at DUCE. A part from providing access to a diverse group of students with different personalities and needs, the use of ICT could also help in identifying the red flag cases for early intervention.

\subsection{Strengths, limitations and directions for future research}

To our best of knowledge, this is the first study not only at DUCE but also in a Tanzanian context to explore undergraduate student teachers experiences with stress and help-seeking behavior from various formal and informal sources of help. Thus, this study extends the existing literature base using Tanzanian sample. Also, this is one of the first studies in the Tanzanian context to illuminate on the level of stress in different students' cohorts and the methods of communication they would prefer to use in seeking for help from college sources. Findings may help college and universities, policy makers and practioners in developing effective and efficient help support services for students in higher learning institutions. 
Despite the strengths, this study also had some limitations. First, the sample constituted only students from DUCE, and given that stressful experiences may vary across contexts, findings should be interpreted with regard to only other Universities or colleges that might have similar characteristics. Second, to obtain the national status on the extent of stress among college students and help-seeking behavior, future studies should broaden the sample to include a large number of higher learning institutions; and the interpretation of findings should consider demographic variables such as gender, age and other student status, which to a larger extent were beyond the scope of this study. Third, the use of a descriptive cross sectional survey design might have provided only a snapshot of the psychosocial stressors and help-seeking behavior problem in the college. Thus, a longitudinal mixed-method research design that begins from the first semester of college enrollment to the final semester should be considered in future studies for an in-depth understanding of the problem.

\section{Recommendations and Conclusion}

The reported higher level of stressful experiences among students illuminates on an urgent need for comprehensive intervention programs that focus on both informal and formal help resources. While strengthening the formal college support services such as counseling, more attention should be given to the informal services that directly or indirectly involve students, for example, students' union or organizations, student leaders, and religious groups. This is consistent to Chang (2008) finding that students favor friends, peers over professional help services. Also, there is a need to have a continuous awareness education on the college help resources and their utilization to both help providers and students. More important, conducive environment, caring relationships, separating counseling from administrative roles and adherence to the ethical principles are not only important but also essential for an effective and efficient college help services. Additionally, with the advancement in communication technologies, there is a need to integrate face to face with electronic communications such as toll free phone calling and e-mail in the provision of help services in colleges and universities in Tanzania.

In conclusion, this study has shed light on student teachers experiences on psychosocial stressors, how they resolve the stressors, and the level of utilization of college help or support resources. In particular, findings have shown that student teachers have reported to have had stressful experiences to the extent of needing assistance. And the most preferred communication method in seeking for help is face to face followed by making a telephone call. Similar to previous studies, this study revealed a lower utilization of the formal college support sources such as counseling and academic advisors compared to the informal support resources such as friends and religious groups. And a lack of awareness, ethical concerns, and cultural factors emerged as the major barriers to help-seeking from the formal college sources of help. Thus, this study provides insight for developing a comprehensive and holistic intervention programs that could buffer students from stress and its' associated negative impacts.

Acknowledgments We wish to thank the first-, second-, and third-year undergraduate students across the three faculties at DUCE and anonymous administrators who made this study possible.

Author Contributions HZO and IM conceived the study and its design. FBM and IM collected the data and coordinated entry into the SPSS software. HZO performed the analysis, interpreted the data and coordinated the writing of the manuscript and its submission to the journal. 


\section{Macrothink

\section{References}

Abdullah, S. S. B. (2011). Help-seeking behavior among Malaysian international students in Australia. International Journal of Business and Social Science, 2(23), 286-291.

Ang, R. P., \& Yeo, L. S. (2004). Asian secondary school help-seeking behavior and preferences for counselor characteristics. An International Journal of Personal, Social and Emotional Development, 22(4), 40-48.

Azen, R., \& Walker, C. M. (2011). Categorical data analysis for the behavioral and social sciences. New York: Routledge.

Barker, G. (2007). Adolescents, social support and help-seeking behavior: An international literature review and programme consulatation with recommendations for action. Geneva, Switzerland: Word Health Organization.

Barry, P. D. (1998). Mental health and mental illness. Philadephia: Lippincott.

Batte, L., \& Dutton, J. (2011). Young tertiary students and help-seeking for health advice. Nursing Praxis in Newzland, 27(3), 31-42.

Best, J. W., \& Khan, J. K. (2006). Research in education. Boston: Pearson.

Bourne, E. J. (2005). The anxiety phobia workbook. Oakland: New Harbinger Publications Inc.

Chang, H. (2008). Help-seeking for stressful events among Chinese college student in Taiwan: roles of gender, prior history of counseling, and help-seeking attitudes. Journal of College Student Development, 49(1), 41-51.

D'Zurilla, T. J. \& Sheedy, C. F. (1991). Relationship between social problem-solving ability and subsequent level of psychological stress in college Students. Journal of Personality and Social Psychology, 61, 841-846.

Eisenberg, D., Gollust, S. E., Golberstein, E., \& Hefner, J. L. (2007). Prevalence and correlates of depression, anxiety, and suicidality among university students. American Journal of Orthopsychiatry, 77(4), 534-542.

Flick, U. (2009). An introduction to qualitative research. London: Sage Publications, Inc.

Fallon, B., \& Bowles, T. (2001). Family functioning and adolescent help-seeking behavior. Family Relations, 50(3), 239-245.

Freeman, M. \& Mathison, S. (2009), Research children's experiences. New York; Guilford Press.

Hyde, J. S., \& Plant, E. A. (1995). Magnitude of psychological gender differences: Another side of the story. American Psychologist, 50, 159-161.

Hyun, J., Quinn, B., Madon, T., \& Lustig, S. (2007). Mental health need, awareness, and use 
of counseling services among international graduate students. Journal of American College Health, 56(2), 109-118.

Hsu, S. (2005). Help-seeking behavior of student teachers. Educational Research, 47(3), 307318.

Kalonge, B. M. (2007). The provision of students counseling services at the university of dar es salaam in the context of university of dar es salaam transformation program (Unpublished master's dissertation). University of Dar es Salaam, Tanzania.

Lahey, B. B. (2004). Psychology: An introduction. Boston: McGraw-Hill.

Lazarus, R. S. \& Folkman, S. (1984). Stress, appraisal and coping. New York: Guilford.

Li, P., Wong, Y. J., \& Toth, P. (2013). Asian International students' willingness to seek counseling: A mixed-methods study. International Journal of Adv Counseling, $35,1-15$.

Mechanics. D. (1962). Student under stress. New York: Free Press of Glen.

Mosha, E. (1990). The extent of educational guidance and counseling services to female students at the university of dar es salaam in Tanzania (Unpublishe master's dissertation). University of Dar es Salaam, Tanzania.

Pallant, J. (2010). SPSS survival manual. A step by step guide to data analysis using the SPSS program (4th. ed.). New York: McGraw Hill.

Pascale, C. (2011). Cartographies of knowledge. Exploring qualitative epistemologies. Los Angeles: Sage Publications, Inc.

Santrock, J. K. (2000). Educational psychology. Boston: McGrwa-Hill.

Sax, L. J. (1997). Health trends among college freshmen. Journal of American College Health, 45, 252-262.

Seif, S. A. (2011). Stress and the coping strategies of students in higher learning institutions in Tanzania: The case of University of Dar es Salaam Main Campus. Journal of the Teofilo Kisanji University, 2(1), 16-32.

Straub, R. O. (2007). Health psychology: A biopsychosoial approach. New York: Worth Publishers.

Stroebel, W. (2000). Social psychology and health. Buckingham: Open University Press.

Thomas, S. P., \& Williams, R. L. (1991). Perceived stress, trait anger, modes of anger expression, and health status of college men and women. Nursing Research, 4, 303-307.

Tinsley, H. E., de St Aubin, T. M., \& Brown, M. T. (1982). College students help-seeking preferences. Journal of Counseling Psychology, 25(5), 523-533. 
Tung, W. (2011). Acculturative stress and help-Seeking behaviors among international students. Home Health Care Management \& Practice 23(5), 383385. doi: 10.1177/1084822311405454. 